\title{
Are junior doctors competent in providing effective feedback to medical students?
}

This article was published in the following Dove Press journal:

Advances in Medical Education and Practice

20 July 2015

Number of times this article has been viewed

\section{Elliott Yann Ah-kee' \\ Aamir Asif Khan ${ }^{2}$}

'Monklands Hospital, Airdrie, North Lanarkshire, UK; ${ }^{2}$ Glasgow Royal Infirmary, Glasgow, Scotland, UK
Correspondence: Elliott Yann Ah-kee Monklands Hospital, Monkscourt Avenue, Airdrie, North Lanarkshire ML6 0JS, UK Email elliottahkee@gmail.com

\section{Dear editor}

Effective feedback is widely recognized as one of the main catalysts for learners to achieve their educational goals and fulfill their potential. Its crucial role in medical education has been well established over many years. ${ }^{1}$ However, previous studies of medical student perceptions show that they are dissatisfied with the feedback received from tutors. The key findings were the lack of feedback on medical students' performances or inadequate feedback when provided. ${ }^{2,3}$

In the UK, provisionally registered doctors (foundation doctors in their first year of training following graduation) are expected by the General Medical Council to teach medical students. In addition, they should also "contribute to the appraisal, assessment or review of students and colleagues". ${ }^{4}$ One of the main issues expressed by medical students is the lack of feedback as mentioned. Foundation doctors often ask for formal feedback from the medical students they teach in order to collect evidence to fulfill teaching requirements of the training program. However, in many cases, feedback to medical students is not always forthcoming and this can potentially hinder their educational development. In addition, literature on the quality of feedback provided by junior doctors is scarce. This raises an important question: are junior doctors competent in giving effective feedback?

As junior doctors with an interest in medical education, we believe that there is a lack of formal training on how to provide effective feedback, within the UK undergraduate curriculum. Junior doctor-led teaching of medical students has become omnipresent at medical schools worldwide. Moreover, many formal teaching programs have recently been set up by junior doctors across the UK. ${ }^{5}$ In fact, it was noted in a recent study by Rashid et $\mathrm{al}^{6}$ that medical students highly value junior doctor-led teaching and found the latter comparable to consultant-led teaching, hence highlighting the importance of feedback provided by junior doctors. Junior doctors are the most approachable members of medical staff for medical students, as they were themselves in the position of medical students on a similar journey of learning not so long ago. As recent medical graduates, junior doctors can offer a unique perspective to medical school exam preparation or life after medical school, hence emphasizing the importance of the symbiosis between medical students and junior doctors.

Several faculty development programs including workshops, have been implemented to encourage faculty members to give feedback to medical students and to improve their skills in doing so effectively. ${ }^{7,8}$ However, such interventions are very 
limited on an undergraduate level in the UK. This forms a basis for future studies on the quality of feedback delivered by junior doctors and efficacy of implementing future interventions.

In conclusion, all the issues regarding feedback given to medical students on their clinical rotations need to be addressed by the medical education departments so that the latter can come away with a valuable learning experience. Furthermore, we believe that incorporating this aspect of medical education into the undergraduate curriculum will acquaint new medical graduates with the necessary tools to provide feedback to medical students in a way that is effective and constructive. In doing so, both safety of patient care and medical education will benefit.

\section{Disclosure}

The authors declare no conflict of interest.
2. Al-Mously N, Nabil NM, Al-Babtain SA, Fouad Abbas MA. Undergraduate medical students' perceptions on the quality of feedback received during clinical rotations. Med Teach. 2014;36 Suppl 1:S17-S23.

3. De SK, Henke PK, Ailawadi G, Dimick JB, Colletti LM. Attending, house officer, and medical student perceptions about teaching in the third-year medical school general surgery clerkship. J Am Coll Surg. 2004;199(6):932-942.

4. General Medical Council. The trainee doctor. London: General Medical Council; 2011.

5. Mabvuure NT, Rodrigues J, Cumberworth A, Mahmud M. Twelve tips for running successful junior doctor-led teaching programmes for medical students. Med Teach. 2013;35(8):628-632.

6. Rashid MS, Sobowale O, Gore D. A near-peer teaching program designed, developed and delivered exclusively by recent medical graduates for final year medical students sitting the final objective structured clinical examination (OSCE). BMC Med Educ. 2011;11:11.

7. Hewson MG, Little ML. Giving feedback in medical education: verification of recommended techniques. J Gen Intern Med. 1998;13(2): $111-116$.

8. Palmer M, Hoffmann-Longtin K, Walvoord E, Bogdewic SP, Dankoski ME. A competency-based approach to recruiting, developing, and giving feedback to department chairs. Acad Med. 2015;90(4):425-430.

\section{References}

1. Boehler ML, Rogers DA, Schwind CJ, et al. An investigation of medical student reactions to feedback: a randomised controlled trial. Med Educ. 2006;40(8):746-749.

Dove Medical Press encourages responsible, free and frank academic debate. The content of the Advances in Medical Education and Practice 'letters to the editor' section does not necessarily represent the views of Dove Medical Press, its officers, agents, employees, related entities or the Advances in Medical Education and Practice editors. While all reasonable steps have been taken to confirm the content of each letter, Dove Medical Press accepts no liability in respect of the content of any letter, nor is it responsible for the content and accuracy of any letter to the editor.

\section{Publish your work in this journal}

Advances in Medical Education and Practice is an international, peerreviewed, open access journal that aims to present and publish research on Medical Education covering medical, dental, nursing and allied health care professional education. The journal covers undergraduate education, postgraduate training and continuing medical education including emerging trends and innovative models linking education, research, and health care services. The manuscript management system is completely online and includes a very quick and fair peer-review system. Visit http://www.dovepress.com/testimonials.php to read real quotes from published authors. 